\title{
Vínculos estabelecidos pelo professor com o Programa Municipal da EJA e a relação- reflexa na formação profissional e pessoal ${ }^{*}$
}

\section{Established bonds between teacher and the Municipal Program of EJA and the reflexive-relation in his professional and personal development}

\author{
Sônia Maria Chaves Haracemiv ${ }^{* *}$
}

\begin{abstract}
RESUMO
O objetivo desta pesquisa foi o de investigar os vínculos estabelecidos pelo professor da Educação de Jovens e Adultos (EJA) com a proposta pedagógica e a equipe de ensino da Secretaria Municipal de Educação (SME), analisando a relação-reflexa no processo de formação profissional e pessoal deste sujeito. Para tanto, buscou-se identificar, no interior da escola, o posicionamento docente quanto aos aspectos afetivos, pedagógicos e normativos, bem como os princípios, a coerência e os valores da proposta da EJA, de que forma ele se identifica com ela e com que autonomia a sustenta. No interior da escola também foi questionado o exercício de autoridade, participação na tomada de decisões, conflitos pessoais, predisposição a mudanças necessárias, aceitação das novas idéias, motivação e valorização frente às condições de trabalho.

Palavras-chave: vínculos; formação pessoal e profissional; relação-reflexa.
\end{abstract}

* O presente artigo é uma versão da Tese de Doutorado intitulada $O$ professor e o programa de EJA de Curitiba: repensando o que é afirmado, negado e sugerido, defendida na PUC-SP.

** Doutora em História e Filosofia da Educação; Professora do Programa de PósGraduação em Educação/UFPR, Linha Cognição, Aprendizagem e Desenvolvimento Humano, na Disciplina Processos Cognitivos e de Aprendizagem de Jovens e Adultos. E-mail: sharacemiv@ufpr.br. 


\begin{abstract}
The objective of this research was to investigate the bonds established between the teacher of the young and adults education program (EJA), with its pedagogical proposal and with the educational team of the Municipal Department of Education (SME), analyzing the reflexive-relation in the process of professional and personal development of this subject. To accomplish this, one searched to identify, inside the school, the teaching positioning regarding the affective, pedagogical and normative aspects, as well as, the principles, the coherence and the values of the EJA's proposal, how the teacher identifies himself with it and with which autonomy he supports it. Inside the school the exercise of authority was questioned, as well as the participation in the taking of decisions, the personal conflicts, the predisposition towards necessary changes, the acceptance of new ideas, the motivation and the valuation related to work conditions.

Key-words: bonds; personal and professional development; reflexive-relation.
\end{abstract}

\title{
Caminhos e gente em construção
}

“(...) um trabalho realizado com gente, jovem ou adulta, mas gente em permanente processo de busca. Gente formando-se, mudando, crescendo, reorientando-se, melhorando." (FREIRE, 1997, p.162).

Repensar a caminhada e os caminheiros que juntos no espaço da escola se desenvolvem e se moldam continuamente como pessoas e profissionais foi um exercício de crítica para todos os sujeitos envolvidos nessa pesquisa, em especial para a autora. Pois, atuando há trinta e nove anos na Educação de Jovens e Adultos, faz reflexão contínua sobre a prática pedagógica e os seus efeitos sobre si e os companheiros que com ela a vivem. Concorda com Freire, que afirma que a prática docente não é superior nem inferior a outra, mas que exige alto nível de responsabilidade ética de que a própria capacitação científica faz parte (FREIRE, 1997, p. 163). 
Vem caminhando no chão das escolas do Paraná desde 1968, inicialmente como monitora do Movimento Brasileiro de Alfabetização, coordenadora da Educação de Jovens e Adultos (EJA) de noventa escolas da Rede Municipal de Ensino (RME) de Curitiba e orientadora de aprendizagem do primeiro Centro de Estudos Supletivo do Estado, hoje Centro de Educação Básica de Jovens e Adultos Potty Lazarotto. Foram dezessete anos nessa mesma escola, que mudou cinco vezes de endereço e a cada mudança exigia nova organização do espaço físico e da vida de todos. Conviveu nesses espaços durante trinta anos, quando aposentou-se da rede estadual de ensino em 1997 e iniciou o doutorado, em busca da compreensão de como foi se forjando como/com profissionais e como/com pessoas adultas, professores, alunos e funcionários, em diferentes condições, uma expressão quantitativa do calor humano, e pressão, como expressão das relações pedagógicas, afetivas e normativas.

São inúmeras as marcas deixadas na trajetória de cada um e do grupo ao construir o processo inicial e contínuo de formação, e que se modificam à medida que há compreensão e análise das ações docentes pelos próprios docentes. Ao confrontar as idéias e a forma de agir, que se construíram ao longo dos anos de convivência e atuação na EJA, permiti conceber o processo formativo como algo que decorre ao longo de toda a carreira dos educadores, que "em vez de tentar fugir de suas próprias ideologias e valores (...) deveriam confrontá-las criticamente de forma a compreender como a sociedade os moldou como indivíduos, no que acreditam e como estruturar (...) os efeitos que têm uns sobre os outros" (GIROUX, 1997, p. 40).

Assim, houve a necessidade de compreender de que forma o processo coletivo, frente à pluralidade de idéias e caminhos, estimula o olhar mais crítico do professor, e em que condições de trabalho se fortalece como sujeito individual e coletivo, tornando-se mais competente para formular alternativas viáveis de transformação do contexto escolar da EJA (ESTEBAN e ZACCUR, 2002, p. 23).

Dada a especificidade dos papéis subjacentes à formação docente, "a análise (...) não pode ser dissociada da reflexão sobre os contextos organizacionais" (SIMÕES, 1995, p. 185); portanto, deve ser compreendida nas experiências e práticas vividas na complexidade das relações interpessoais (professores, alunos, equipe pedagógica e administrativa) e interinstitucionais (Escola e Secretaria Municipal de Educação).

$\mathrm{O}$ intuito de debruçar-se sobre esse tema, foi o de analisar os vínculos estabelecidos entre os professores, a proposta da Educação de Jovens e Adultos (EJA) da Secretaria Municipal de Educação de Curitiba (SME) e a 
escola, buscando identificar na trajetória do professor a relação-reflexa no processo de formação profissional e pessoal. Para tanto, foi necessário investigar como o professor reconhece o seu desenvolvimento pessoal e profissional, sendo parte de um todo com especificidades de conhecimentos e atitudes. Perceber que está no todo, e como este interfere substancialmente nas partes e elas no todo, só se torna concreto via o diálogo permanente.

O trabalho buscou conhecer o "jogo de máscaras e espelhos com que os docentes se confrontam consigo próprios, no interior da escola, (...) e como as duas dimensões, a pessoal e a profissional, se interpenetram e interferem, produzindo uma ambivalência" (ZAVALLONI, 1973, p. 23), aqui denominada relação-reflexa. Para tanto, em 2000, a pesquisadora, no seu doutoramento, tomou os dados levantados por um questionário com 40 questões, elaborado e aplicado pela Prefeitura Municipal de Curitiba em 1998, cujo objetivo foi avaliar o Programa de Educação de Jovens e Adultos referente à Fase I - Alfabetização de $1^{\text {a }}$ à $4^{\text {a }}$ séries de Curitiba de EJA, adotado desde 1991, até então não avaliado. Foram ouvidas as falas dos 228 professores das 77 escolas municipais. Ao organizar os itens do questionário, a SME esclarecia no alto da página: ele seria um instrumento auxiliar de coleta de informações sobre algumas variáveis-chave que permitiriam avaliar as motivações, preocupações e condições atuais dos professores da EJA da Rede Municipal de Ensino (RME). Foi utilizada a escala de Likert, de cinco possibilidades de escolha, o que significa que cada indivíduo escolheu cinco questões de acordo-desacordo e imparcialidade. A SME buscou, ao elaborar o questionário, campos de afirmações positivas, negativas e neutras que refletissem os sentimentos dos docentes. Os referenciais de análise foram o conteúdo do Programa de EJA da RME e o posicionamento dos professores frente aos itens que constituíram os eixos temáticos. Serviram de fios na tecitura desse trabalho os seguintes eixos: valorização pessoal e motivação, vinculação teoria à prática, relações individuais e institucionais, mudanças de paradigma, autonomia e coerência, e autoridade e participação.

\section{Valorização pessoal e motivação}

O Programa de EJA enfatiza que: "a atitude do professor está em íntima conexão com as concepções de homem e de sociedade que ele tem 
e que por sua vez sustentam a prática pedagógica", cuja "metodologia (...) deve estimular nos alunos as atitudes críticas" (sem grifo no original) (CURITIBA, 1998, p. 16).

A valorização pessoal envolve atitudes e motivações, pois, como afirma Freire (1997), a formação e a atuação docente não podem ficar distantes do reconhecimento do valor das emoções, da sensibilidade, da afetividade. Além de esperar a valorização da escola, é preciso que o próprio professor se valorize por meio de seu aperfeiçoamento pessoal e profissional.

Definir atitude é uma tarefa difícil, mas, ao tratar de medidas de atitudes por meio de escalas, conclui-se que poderia ser definida como "estados mentais subjacentes, capazes de influenciar a escolha de ações que a pessoa faz e capazes de manter consistência através destas ações" (MOREIRA, 2002 , p. 3). A atitude é o que realmente interessa, enquanto a opinião só tem relevância se for interpretada como símbolo da atitude. Pode-se utilizar as opiniões como instrumentos para medir as atitudes" (THURSTONE, apud GLANTZ, 2000, p. 1).

A atitude do professor pode ser entendida como grau de afeto positivo ou negativo (gostar ou não gostar) associado com algum objeto psicológico (objeto de interesse). Envolve o componente cognitivo, relacionado aos conhecimentos e às crenças; o componente afetivo, relacionado aos gostos e preferências; e o componente comportamental, referente à tendência, à ação, às intenções diversas que movem as pessoas (THURSTONE, 1946).

A partir da prática pedagógica sustentada pelas concepções de homem e de mundo que o professor tem, ele vai mover-se, pois a palavra motivação, que deriva do latim movere, significa mover e é um "fenômeno psicológico que consiste na tensão subjetiva persistente, fundamentada em fatores internos ou de contexto, que provocam no indivíduo formas de comportamento, visando satisfação das necessidades" (ROSA, 1994, p. 45).

O posicionamento dos professores foi de envolvimento e satisfação, uma vez que muitos concordaram totalmente, um número menor apenas concordou, e um menor grupo concordou parcialmente com a afirmação: sinto-me valorizado profissionalmente por trabalhar com a EJA.

Cacciola (2000) afirma, porém, que na escala de Likert deve-se levar em conta a reação ao objeto ou ao sujeito; ou seja, o entrevistado reage ao instrumento e a quem o aplica. Portanto, é preciso questionar se esse posicionamento estaria indicando satisfação ou seria uma atitude cômoda ou dormente, uma vez que o professor estava diante de afirmações elaboradas pela SME. 
Por que a dormência? Ela pode ser conseqüência de vários fatores, mas parece que um dos mais marcantes é o chamado desvinculamento entre o que se pensa e o que se diz. Os professores poderiam não se sentir despertados para dizer o que realmente pensam, nem a desenvolver o pensamento crítico. A dormência pode ser atribuída ao distanciamento entre "a teoria aprendida nos cursos de formação [que] ocorre desvinculada de situações concretas que articulam o sentido e o significado para essas duas instâncias epistemologicamente não separadas" (GRELLET, 1999, p. 2).

Então, quando o professor afirma concordar parcialmente que se sente valorizado e seguro, na verdade pode estar dizendo: prefiro me posicionar assim para não criar problemas, pois, com a formação que recebi/recebo e com as condições de trabalho é o melhor que posso fazer? Isso poderia indicar o momento de crise que o profissional da educação vive na escola. Essa crise pode tanto reforçar a atitude de passividade como predispor alguns professores a sonhos libertadores, como explica Freire:

Os que estão abertos à transformação sentem um apelo utópico, mas também sentem medo. (...) Quem protesta, agora, torna-se individualmente mais visível e, portanto, mais vulnerável. Se está na oposição, em vez de estar seguro dentro do consenso do establishment (currículo oficial), arriscase a ser despedido (...) ou não conseguir os cursos que quer ministrar, ou para o horário que quer, ou a licença que pediu, ou até mesmo, em alguns casos, fica-se na mira dos grupos ultraconservadores (FREIRE, 1986, p. 68).

Realmente, há a hipótese do medo, mesmo que muitos não falem abertamente, pois é constrangedor admitir que se teme o risco profissional e político que acompanha a oposição e, talvez, de posicionar-se e não ter a aceitação, ficando sem o apoio da equipe da escola e da SME.

A presente análise enfatiza a necessidade de que se investigue mais essa situação através da escuta e do olhar atento sobre o que os professores podem querer transmitir, lembrando que "podemos descobrir nuances, categorias e até fatos que não estavam assim tão escondidos", ou seja, "escutar" os fenômenos que parecem difusos na vivência cotidiana (PERRENOUD, 2001, p. 122). De outro lado, os profissionais, ao manterem-se comedidos na posição de apenas concordo, podem não estar plenamente conscientes de seus senti- 
mentos com relação a um instrumento de pesquisa, mas sentem-se misturados e confusos, dificultando a própria avaliação.

Por último, questiona-se se, quando os professores afirmaram que desenvolvem na escola um trabalho que corresponde à concepção que têm de educação, não poderiam estar fazendo um recuo tático para descobrir uma nova forma de trabalho que não receba alguma forma de repressão, já que, como questiona Freire (1986), "existem autoridades que policiam o professor"?

Os questionamentos levantaram a possibilidade de auxiliar no aprofundamento de tais respostas sobre o despertar da consciência crítica também da SME sobre a formação dos professores e destes sobre seu trabalho docente.

\section{Vinculação teoria à prática}

O Programa de EJA (CURITIBA, 1998, p. 16) afirma que "o currículo é dinamizado organicamente pelo professor, que liga o saber trazido pelo aluno com o saber sistematizado, vinculando prática e teoria, unindo todos os elementos que intervêm no processo ensino-aprendizagem" (sem grifo no original).

A vinculação teoria-prática é possível se houver reflexão crítica sobre a prática. E esta reflexão "se torna uma exigência da relação teoria-prática sem a qual a teoria pode ir virando blablabá e a prática, ativismo" (FREIRE, 1997, p. 24). Desse modo, questiona-se: seria suficiente, no modo como parece colocado pela SME, que a ligação do saber do aluno com o saber sistematizado realize essa junção da teoria e prática? É preciso também a reflexão crítica que envolve o aspecto de "quem ensina aprende ao ensinar e quem aprende ensina ao aprender. Se o aprendiz não se torna capaz de recriar ou de refazer o ensinado, e se o ensinado não foi apreendido, inexiste validade no ensino" (FREIRE, 1997, p. 25-26).

Também no pensamento de Ardoino (1971) está presente a preocupação com o saber aprender e com o saber ser: a educação deve se subsidiar não mais na 'tradição de um 'saber' ou de um 'saber-fazer', mas da comunicação duma 'experiência', da aquisição de um 'saber viver' ou de um 
'saber-ser'. A ação formativa [deve] produzir um 'conhecimento experimental' dos problemas, que se pode opor ao conhecimento intelectual".

Quanto à vinculação teoria e prática, o posicionamento dos professores restringe-se ao intervalo situado entre a concordância total e a concordância parcial. Os professores mostram-se consoantes com a clareza, a consistência, a coerência das propostas da SME e com os princípios e valores estabelecidos pelo programa. Consideram que a escola em que trabalham aceita as mudanças propostas e sustentam os valores e princípios estabelecidos pelos profissionais da SME, os mentores do programa EJA de Curitiba. No entanto, parecem contradizer-se, pois consideram que há necessidade de mudanças na atual estrutura da EJA.

Essa possível contradição origina a seguinte questão: o que a SME entende por estrutura de EJA? Segundo os dicionários, estrutura significa $o$ que é fundamental ou essencial, estável e relevante (em oposição ao que é acessório, ocasional ou variável). Se for essa a definição subentendida pela SME ao aplicar o questionário aos professores, todo o conteúdo com o qual eles concordaram anteriormente perde seu significado, pois estariam negando o que afirmaram.

De outro lado, poderia não haver a contradição propriamente dita, mas os professores poderiam estar manifestando afeto positivo e negativo associados ao mesmo objeto psicológico (o programa), o que é comum ocorrer. Moreira (2002, p. 4), ao discorrer sobre os modos de medir atitudes, afirma que "em medidas nas quais o material do qual se tiram inferências consiste de declarações pessoais sobre crenças, sentimentos e comportamento, com relação a um objeto ou classe de objetos", pode ocorrer essa ambigüidade. Se ela ocorre em relação ao programa, como os professores se submeteriam a ele em sua solicitação de unir teoria e prática?

Se a união teoria e prática depende da capacidade de reflexão crítica do professor e se, como afirma Martins (2000), um dos fundamentos da moderna teoria da aprendizagem de adultos é aprenderem por meio da análise de suas experiências, então uma das mudanças da atual estrutura da EJA reivindicada pelos professores pode estar nessa capacidade de reflexão crítica. 


\section{Relações individuais e institucionais}

O Programa de EJA (1998) afirma: "A metodologia da EJA deve ser orientada por uma ótica interativa, promovendo o diálogo entre o saber popular e o saber erudito" (sem grifos no original). Para haver a superação do saber pelo saber-fazer, é preciso transcender o diálogo entre o saber popular e o erudito, passando para o saber questionador. A esse propósito, é importante lembrar o argumento de Freire apud Silva (2001) ao comentar o conceito antropológico de cultura: que o ato de conhecer é consciência de alguma coisa, envolvendo as consciências das próprias atividades e o conceito de si mesmo que distingue o ser humano dos animais.

Nessa concepção, não se faz distinção entre cultura erudita e popular, entre "alta" e "baixa" cultura. A cultura não é definida por qualquer critério estético ou filosófico. É simplesmente o resultado de qualquer trabalho humano. Mesmo que, implicitamente, essa crítica do conceito de cultura permita a Paulo Freire desenvolver uma perspectiva curricular que, antecipando-se à influência posterior dos Estudos Culturais, "apaga as fronteiras entre cultura erudita e cultura popular" (sem grifo no original) (SILVA, 2001, p. 61-62).

De certa forma, tem-se a impressão, pelo mesmo enunciado do Programa, que os mentores, representados na prática por seus dirigentes, se ausentam das relações educativas, especialmente quando professores e alunos encontram dificuldades para desenvolver o trabalho pedagógico, frente às condições oferecidas na escola.

A leitura dos posicionamentos dos professores evidencia que os professores concordam parcialmente, no que diz respeito à administração dos conflitos pessoais e quanto à percepção do tratamento na escola, em relação à função que exerce o funcionário. Mas pode-se questionar se realmente os professores percebem que são tratados da mesma maneira, independentemente da função que exercem. Se assim realmente ocorresse, será que as questões de valorização pessoal não teriam tido concordância total em lugar do concordo parcialmente?

É importante observar que os professores concordaram que o relacionamento entre os professores de EJA e os diversos setores da escola é, na sua maioria, de boa qualidade. Cabe uma pergunta, a partir da própria experiência de EJA: seria essa concordância totalmente verdadeira? Com exceção das sete maiores escolas, que têm estrutura de funcionamento à noite, as demais não têm. À noite estão fechadas a biblioteca, a secretaria, 
a sala de multiuso, a sala de jogos e a sala de mapas. A professora exerce vários papéis por falta de infra-estrutura. Geralmente só permanecem na escola o vigia, os docentes e os alunos. Quando os dados dos alunos do período noturno são solicitados, é necessário ir à SME, pois eles não ficam arquivados na escola, configurando-se, portanto, o desvinculamento da EJA com os demais setores da escola.

Nestas condições de trabalho, por que os docentes estariam concordando que há qualidade no relacionamento entre eles e os demais setores da escola? É importante lembrar que um dos componentes das atitudes é o cognitivo, relacionado ao conhecimento do objeto (programa), às crenças pessoais e às experiências prévias que permanecem na memória (THURSTHONE, 2000).

Nesse contexto, conflitos interpessoais, possibilidades de emitir opiniões e de receber tratamento com eqüidade, boa qualidade do relacionamento entre os profissionais e boa comunicação entre os professores de EJA e os da escola podem trazer boas ou más lembranças, conforme o modo como a questão é interpretada. Portanto, poderiam preferir optar pelo cômodo concordo.

É importante lembrar que professores, alunos e funcionários são seres de relações, como afirma Freire (1986), "o homem está no mundo e com o mundo. Se apenas estivesse no mundo não haveria transcendência nem se objetivaria a si mesmo. Mas como pode objetivar-se, pode também distinguir entre um eu e um não-eu, por isso consegue relacionar-se; sair de si, projetar-se nos outros, transcender." Esses relacionamentos com os outros, no entanto, exigem a consciência do inacabado porque a "história em que me faço com os outros (...) é um tempo de possibilidades e não de determinismo". Mas esse tempo é tempo de possibilidades condicionadas pela herança genético-sociocultural e histórica que faz das pessoas seres responsáveis pelas opções existenciais e posturas assumidas na prática docente (FREIRE, 1997, p.58).

Assim, por mais motivos que os professores tivessem para discordar, algo deveria ser feito para sanar as dificuldades sentidas quanto à falta de disponibilidade dos recursos educativos na EJA, comprometendo as condições de trabalho. O saber ser e viver implica a presença de outro. É com o outro que "o indivíduo chega a saber ser, a saber tornar-se, sendo, portanto, na interação que o indivíduo sabe-se sendo. Na troca e no vivido é que se aprende a saber ser e este, além de ser o melhor modo de unir teoria e prática, é também o principal fundamento da educação" (MARTINS, 2000, p. 4). 


\section{Mudança de paradigmas}

O Programa afirma que "a educação transforma a prática social de modo indireto e mediato, no próprio processo de transmissão-assimilação do saber, quando este, ao modificar o nivel de consciência do educando no próprio modo de aprender, possibilita-lhe maior grau de liberdade e de atuação na sociedade" (sem grifo no original) (CURITIBA. SME, 1998, p. 17). Este texto aponta que é pela transmissão-assimilação do saber que se processa a modificação do nível de consciência do educando, para que tenha liberdade de agir na sociedade, e "é pela reflexão crítica que se responde aos problemas existenciais e se age com liberdade. Uma opção dessa reflexão crítica sobre a realidade pode ser a de analisar a vida e a linguagem dos estudantes como textos sociais, pois apresentam motivos, personagens e imaginário como pistas para seu significado, indicando a direção das mudanças a serem efetuadas" (SHOR e FREIRE, 1986, p. 35).

Comentam ainda:

Eu pesquiso as palavras faladas e escritas dos estudantes para saber o que eles sabem, o que eles querem, e como eles vivem. Suas falas e textos são um acesso privilegiado a suas consciências. Examino as palavras e os temas que são mais importantes para eles, pois assim terei materiais da realidade para estudos em classe (SHOR e FREIRE, 1986, p. 20).

Essas indicações parecem constituir atos simples, mas exigem talvez a mudança interior do professor para praticá-las e mudanças em seu próprio nível de consciência para possivelmente exercer a consciência crítica em relação à educação de EJA e do Programa da RME.

Quanto à concordância total dos professores frente à consideração de que há necessidade de mudanças na atual estrutura da EJA, vê-se que os docentes têm consciência de que precisam mudar. Mas, o que é ter consciência de mudança? Talvez se entenda que algo não está correto e por isso não se está satisfeito. No caso, os processos metodológicos talvez não satisfizessem estes docentes. Então pergunta-se: ao concordar com essa afirmação, os professores estariam colocando uma resposta não perturbadora, somente, ou estariam denunciando que o sistema escolar, 
apesar de ter competência e autonomia para mudar, não tem vontade política para fazê-lo?

Além disso, se há equilibrada harmonia entre as manifestações pessoais, pedagógicas e normativas da escola, haveria necessidade de mudar? Diante do receio ou medo que os professores parecem expressar, vale lembrar Freire (1986), ao afirmar que o medo não pode imobilizar o sonho político, ou o sonho das mudanças na educação. Para não renunciar ao sonho, a alternativa seria que o professor buscasse caminhos criativos para transformar a prática, adotando atitudes experimentais em suas aulas, pesquisando seu campo de ação para ver resultados e limites de sua intervenção, especialmente porque os conteúdos resolvidos devem auxiliar na compreensão da realidade.

Acreditar que o conteúdo programático da educação não é uma doação ou imposição, mas a devolução organizada, sistematizada e acrescentada ao povo daqueles elementos que este lhe entregou em forma desestruturada. O que ele [Paulo Freire] destaca é a participação dos educandos nas várias etapas de construção desse "currículo programático", que deve ser feito em conjunto pelo educador e pelos educandos. Esse conteúdo programático deve ser buscado, conjuntamente, naquela realidade, naquele mundo que constitui o objeto do conhecimento intersubjetivo (SILVA, 2001, p. 61).

Se o programa enfatiza que os conteúdos desenvolvidos devem auxiliar na compreensão da realidade, e se a realidade fala da mudança de paradigmas, concorda-se que os professores não precisam renunciar ao sonho. Por que, então, os professores concordam que as pessoas em geral, na escola, têm predisposição parar mudar? Esse posicionamento pode, propositalmente, como enfatiza Moreira (2002), revelar um silenciar sentimentos ou atitudes individuais.

\section{Autonomia e coerência}

O Programa de EJA (1998) afirma que "o Conselho de Classe se constitui numa importante instância de decisão ao diagnosticar e analisar 
os seus resultados, atribuindo-lhes valor, com vistas à melhoria da prática educativa" (sem grifo no original). A melhoria da prática educativa, conforme Freire (1997), só vai se realizar se todos os envolvidos com a educação se sentirem incluídos e se for respeitada a leitura de mundo de cada um como ponto de libertação e autonomia do ser pensante e influente no seu próprio desenvolvimento, libertando o pensamento das tradições desumanizantes, aspectos estes indicativos da pedagogia da autonomia. Ao tratar do Projeto político pedagógico da escola, Veiga (2000) remete o conceito de autonomia "para regras e orientações criadas pelos próprios sujeitos da ação educativa, sem imposições externas". Destaca que autonomia e liberdade fazem parte da própria natureza do ato pedagógico.

Resta questionar: o Conselho de Classe teria as características de uma gestão democrática, com ampla participação dos representantes dos diferentes segmentos da escola nas decisões/ações? Pois, "a participação ampla assegura a transparência das decisões, fortalece as pressões para que sejam legítimas, garante o controle sobre os acordos estabelecidos e, sobretudo, contribui para que sejam contempladas questões que de outra forma não entrariam em cogitação", ou seja, agiriam com autonomia e coerência (MARQUES apud VEIGA, 2000, p. 18).

A coerência profissional, comprometimento existencial do qual nasce autêntica solidariedade entre educador e educandos, significa que ninguém pode se contentar com um modo neutro de estar no mundo, já que ensinar é uma forma de intervenção nele (FREIRE, 1997, p. 125).

No que se refere ao que os professores dizem a respeito do programa, quanto à autonomia, à proposta e aos princípios estabelecidos pela EJA, em primeiro lugar, concordam parcialmente que há autonomia para tomar decisões, talvez porque podem posicionar-se e emitir opiniões referentes aos encaminhamentos do processo educativo. Mas, emitir opiniões não é garantia de que elas sejam aceitas. Pode garantir, no entanto, que os professores se sintam participantes. Enquanto eles somente emitem opiniões, a EJA estabelece princípios e valores que os professores precisam sustentar.

Mas resta ainda um questionamento: será que os professores repensaram o verbo utilizado discutir no lugar de estabelecer, no momento do posicionamento à questão? É importante analisar com cuidado os vocábulos utilizados, que ideologicamente podem fazer os professores crer que são autônomos para a tomada de decisões, enquanto, na prática, só poderiam agir sustentando o já estabelecido, ou seja, escolher entre opções já determinadas. 
Os professores que concordam que todos os profissionais têm consciência de que da qualidade de seu trabalho depende o sucesso de toda a escola, concordam também que os diferentes setores da escola cooperam entre si em função do objetivo comum, a educação, que há coerência entre a proposta da EJA e o trabalho efetivo com o aluno. Essas afirmações, especialmente aquela da coerência, podem revelar que os professores não duvidam de que há coerência entre o programa de EJA e o trabalho deles. Mas, como se explica que, antes, eles afirmaram que os paradigmas ou metodologia utilizados precisavam ser modificados?

Esse afirmar/negar pode apontar dúvidas ou ambigüidades sobre se existe ou não coerência entre a proposta da EJA e o trabalho efetivo com o aluno. Se há essa dúvida, por que, nessa questão, se posicionam concordantes quanto à coerência? Na verdade, estariam negando-a? Ao se observar a concordância a respeito de que os valores e princípios estabelecidos pela EJA são sustentados da mesma maneira pelos professores, percebe-se que a afirmação pode indicar negação. Como eles concordam que os docentes sustentam os valores e princípios estabelecidos pela EJA, se afirmaram ter consciência da necessidade de que a EJA mude sua forma de agir?

Os professores concordam que todos os profissionais têm consciência de que da qualidade de seu trabalho depende o sucesso de toda escola. Seria de se esperar que diante de um tão extraordinário consenso da necessidade de mudança na EJA não houvesse contradições, ou seja, haveria o posicionamento de discordância nessa questão, mas isso não ocorreu.

Quando isso acontece, a resposta pode estar, segundo Cacciola (1988), na afirmação de que grande parte dos professores de EJA não se sentia à vontade para desviar-se da opção concordo no questionário aplicado. Esse fenômeno reflete, talvez, a intensa pressão que os professores sofrem de seus chefes imediatos para agir e comportar-se como os superiores desejam que sejam tratados os subordinados e punindo aqueles que tentam desviar-se do rumo traçado.

\section{Autoridade e participação}

O Programa de EJA (1998) afirma que "é imprescindível a mediação do professor estabelecendo conexões entre o conhecimento oriundo da prá- 
tica do aluno e o conhecimento sistematizado". Apesar de a mediação do professor ser discutida, hoje, e que orienta reflexões e ações para que ele passe de mediador a orientador, o programa prevê que o papel do professor é fazer a conexão entre o conhecimento da prática do aluno e o conhecimento sistematizado. Como a mediação do professor é vista por ele?

Considerando que "é a própria experiência dos educandos que se torna a fonte primária de busca dos temas significativos ou temas geradores que vão constituir o conteúdo programático do currículo dos programas de educação de adultos" (FREIRE apud SILVA, 2001, p. 60), há diferença de fazer conexões, como as propostas no programa.

É preciso que a autoridade escolar não se revista de poder autoritário. Autoridade, termo que no latim auctoritate significa aucto (próprio), ritate (idade, próprio do tempo) não significa um tempo chronos, mas o tempo kairós. Não é o tempo em que a pessoa está no magistério, mas é o saber fazer o tempo, na hora certa, na medida certa, fazer as devidas colocações, relações. Autoridade e participação estão relacionadas, porque só tem real autoridade quem é sujeito próprio de seu tempo, quem está ativo, quem é capaz de fazer a história, questionar, participar, não impor. A autoridade sempre anda junto com a liberdade, pois "a liberdade é uma relação e, como tal, deve ser continuamente ampliada. O próprio conceito de liberdade contém o conceito de regra, de reconhecimento, de intervenção recíproca. Com efeito, ninguém pode ser livre se, em volta dele, há outros que não o são!" (HELLER apud VEIGA, 2000, p. 19). Desse modo, para que os professores se sintam livres e autônomos, precisam se sentir participantes.

Ao se realizar a leitura dos questionários, pode-se pensar que as questões estariam afirmando que as autoridades (diretoria da SME, do NRE e vice-diretorias) deixam os professores livres (independem de permissão) para trocar opiniões sobre questões de trabalho. Mais que isso, estariam estimulando a participação dos docentes nas discussões sobre processos e sistemas educacionais, criando a possibilidade do surgimento de novas idéias. Mas, frente à questão de que as decisões priorizadas pelo nível central da SME favorecem o desenvolvimento do EJA, cria-se outra possibilidade de interpretação. Os professores posicionaram-se na concordância parcial.

Pergunta-se: estariam eles duvidando de que as decisões priorizadas pela SME estimulam realmente o desenvolvimento da EJA, ou teriam certeza absoluta? Aqueles profissionais que concordaram parcialmente estariam deixando de lado a necessidade de mudança da estrutura da EJA? E os demais, estariam negando o que afirmaram anteriormente? 
De outro lado, concordam que a autoridade na escola objetiva facilitar o trabalho com o aluno e o desenvolvimento da pessoa, que têm liberdade para trocar opiniões sobre questões de trabalho com o vice-diretor, NRE e nível central da SME, que o vice-diretor e representantes estimulam a participação dos professores nas discussões sobre processo e sistemas educacionais, e que, em virtude da liberdade e da aceitação das mudanças, as novas idéias e a criatividade encontram um fértil espaço entre os professores e o nível central da SME.

Diante das várias questões colocadas, questiona-se: quem prioriza as decisões da EJA? Elas não deveriam ser tomadas de forma participativa por todos os envolvidos? As mudanças não deveriam partir dos grupos? As novas idéias e a criatividade surgem dos professores? Como se dão as relações de poder? Se as decisões já vêm priorizadas pelo nível central da SME, como os professores estariam discutindo os processos decisórios? Se a autoridade é exercida no sentido de facilitar o processo, como os professores estariam participando desse processo?

Mas é preciso repensar por que eles se posicionaram de modo contrário na questão que tratava das decisões priorizadas pelo nível central da SME favorecendo o desenvolvimento da EJA. Na verdade, já disseram que não favorece quando se colocaram a favor da mudança da estrutura da EJA. Nesse caso, recomenda-se uma reflexão sobre o conceito de consciência.

É preciso ter consciência de que a dominação no interior da escola efetivase por meio das relações de poder que se expressam nas práticas autoritárias e conservadoras dos diferentes profissionais, distribuídos hierarquicamente, bem como por meio das formas de controle existentes no interior da organização escolar. Como resultante dessa organização, a escola pode ser descaracterizada como instituição histórica e socialmente determinada, instância privilegiada da produção e da apropriação do saber (...) por outro lado é local de desenvolvimento da consciência crítica da realidade (VEIGA, 2000, p. 21).

A autoridade sem participação restringe a caminhada conjunta, porque a história é feita com os outros, num tempo, como mencionado anteriormente, de possibilidades e não de determinismo (FREIRE, 1997), ou seja, todos deveriam ter seu próprio tempo de falar, fazer, pensar e repensar. 


\section{Considerações finais}

No presente trabalho, há pouco que concluir e muito a refletir. A impressão que se tem é que está apenas iniciando, e de fato está, pois a educação é um processo dinâmico e sempre há muito que aprender. Essa postura responde ao objetivo dessa pesquisa que se propunha a pensar a respeito dos profissionais que atuam na EJA, procurando identificar os vínculos existentes entre o professor e o programa EJA da RME - Curitiba.

Ao se estabelecerem correlações, observa-se que, na avaliação dos professores, as relações entre as propostas do programa de EJA e as ações da equipe de ensino da SME para desenvolver o profissional e a pessoa do professor são ações reflexas, isto é, refletem-se (reproduzem-se) e voltam, ou modificadas por essas relações ou contestadas. Entendem-se por reflexas as ações da equipe da SME, da escola e do programa.

Neste trabalho, as afirmações e/ou posicionamentos dos professores a respeito das ações da SME confirmam que há sim reflexão (reprodução) das ações da equipe de EJA no programa, como ocorre com uma imagem que se espelha na água. Por isso, o desenvolvimento do profissional docente, que atende o programa de EJA, fica prejudicado. Em outras palavras, se o programa é imagem da equipe de SME, significa que o ser professor foi marginalizado, uma vez que ele não deve ter participado da elaboração do programa e, se não há participação, há, de algum modo, imposição. Questiona-se, portanto: não seria interessante a SME saber a opinião dos professores sobre a imagem dela, ao invés de traçar possíveis mudanças a serem efetuadas na EJA e na formação do ser professor sem consultá-los? E os professores, ao perceberem isso, não teriam preferido simplesmente entrar no seu jogo e se posicionaram de modo indefinido?

A afirmação de que as relações pedagógicas e normativas da escola facilitam o processo de trabalho docente visando ao desenvolvimento dos profissionais que atuam no programa da RME - Curitiba foi aceita parcialmente, pois seu posicionamento a respeito foi ora a favor ora contra, o que modifica um posicionamento tido como parcialmente concordante em denunciante de que há algo que precisa de mudança radical, ou melhor, estrutural, como afirmaram.

Por esses motivos, na avaliação dos professores, as condições atuais do trabalho docente no programa de EJA na RME são questionáveis. De outro lado, eles indicam uma predisposição para mudança somente parcial- 
mente confirmada, pela presença de dúvidas e indefinições, não deixando claro se as querem realmente, ou se receiam que as mudanças envolvam riscos profissionais (demissões, discriminações, etc.).

Enfim, pode-se afirmar que grandes lições foram aprendidas com a realização deste trabalho, principalmente porque é quase impossível concluir algo que envolve posicionamentos e que, portanto, as conclusões se efetivam em novas perguntas que poderiam ser respondidas por outros trabalhos que se sugere sejam realizados. Termina-se com uma pergunta final: em educação, quando não há respostas definidas ou convencionais, o mais sábio não seria simplesmente ouvir o silêncio das entrelinhas?

Como no início, aqui também há concordância com Freire (1997) ao dizer que "a consciência do mundo e a consciência de si como ser inacabado necessariamente inscrevem o ser consciente de sua inconclusão num permanente movimento de busca. (...). É na inconclusão do ser, que se sabe como tal, que se funda a educação como processo permanente", ou seja, a autora deste trabalho reviveu a aprendizagem da importância de se reconhecer como ser inacabado, com necessidade de renovar seu permanente movimento de busca.

\section{REFERENCIAS}

ARDOINO, J. Psicologia da educação: na universidade e na empresa. São Paulo: HerderEdusp, 1971.

CACCIOLA, S.; GIORDANO, A. Contributo al dibattito sulle scale Likert basato sull'analisi di interviste registrate. Milano: Franco Angeli, 1988.

CURITIBA. Prefeitura Municipal de Curitiba. Secretaria Municipal de Educação(SME). Programa de Educação de Jovens e Adultos. Curitiba, 1998.

FREIRE, P. Pedagogia do oprimido. 29. ed. Rio de Janeiro: Paz e Terra, 1986.

.Pedagogia da autonomia: saberes necessários à prática educativa. São Paulo: Paz e Terra, 1997.

GIROUX, H. A. Os professores como intelectuais: rumo a uma pedagogia da aprendizagem crítica. Porto Alegre: Artes Médicas, 1997.

GRELLET, V. Notas conceituais, 1999. In: GOMES, R. de C. G. Educação à distância: uma alternativa para a formação de professores e demais profissionais na sociedade do conhecimento. Florianópolis, 2000. Disponível em: <http://www.educacao.ufpr.br.> 
Acesso em 26 nov. 2001.

HARACEMIV. S. M. C. O professor e o Programa de EJA de Curitiba: repensando o que é afirmado, negado e sugerido. 181 f. Tese de Doutorado em História e Filosofia da Educação, PUC-SP, 2002.

INSTITUTO DE PESQUISA E PLANEJAMENTO URBANO. Curitiba em dados. Curitiba: IPPUC, 1996.

MARQUES, M. O. A formação do profissional da Educação. Ijuí: UNIJUÍ 1998.

MARTINS, J. B. Refletindo sobre a formação de professores: aproximações psicanalíticas. Londrina: Universidade Estadual de Londrina, 2000. Disponível em: $<\mathrm{http}$ :// www.sspp.net/archive/papers/3(1)martins.htm>. Acesso em 2 jan. 2002.

MOREIRA, D. A. Medidas de atitudes através de escalas. Disponível em: <http:// www.recap.br/amoreira/textos-metodologia_04.htm>. Acesso em 5 jan. 2002.

PERRENOUD, P. (Org.). Formando professores profissionais: quais estratégias? Quais competências? 2. ed. rev. Porto Alegre: Artmed, 2001.

PAIVA, J. Tramando concepções e sentidos para redizer o direito à educação de jovens e adultos. Revista Brasileira de Educação, Campinas, v. 11, n. 33, p. 519-539, set.-dez. 2006.

ROSA, L. Cultura empresarial: motivação e lideranças. Lisboa: Presença, 1994.

SEVERINO, J. et al. Documento norteador para a elaboração das diretrizes curriculares para os cursos de formação de professores, 1999. Disponível em: <http: //www. Educacao.ufpr>. Acesso em 26 nov. 2001.

SILVA, E. T. da. Os descaminhos da escola: traumatismos educacionais. 6. ed. São Paulo: Cortez, 2001.

SILVA, T. T. da. Documentos de identidade: uma introdução às teorias do currículo. 2. ed. Belo Horizonte: Autêntica, 2001.

SIMÕES, H. R. Dimensões pessoal e profissional na formação de professores. Aveiro: Cidine, 1995.

SHOR, I.; FREIRE, P. Medo e ousadia. Trad.: Adriana Lopez. Rio de Janeiro: Paz e Terra, 1986.

THURSTHONE, L. L. Comment. American Journal of Sociology, n. 52, p. 39-50, 1946.

VEIGA, Ilma Passos A. (Org.). Projeto político-pedagógico da escola: uma construção possível. 11. ed. Campinas: Papirus, 2000.

ZAVALLONI, M. A identidade um conceito à procura de uma ciência. In: ESTRELA, M. T. (Org.). Viver e construir a profissão docente. Lisboa: Porto, 1997. 
ZEICHNER, K. A formação reflexiva de professores: idéias e práticas. Lisboa: Educa, 1993.

. Formando professores reflexivos para uma educação centrada no aprendiz: possibilidades e contradições. In: STEBAN, M. T.; ZACCUR, E. (Orgs.). Professorapesquisadora - uma práxis em construção. Rio de Janeiro: DP\&A, 2002.

ZEICHNER, K.; LISTON, D. Reflective teaching. Mahwah: Erlbaum, 1996.

Texto recebido em 05 de nov. 2006 Texto aprovado em 12 de jan. 2007 